\title{
A NOTE ON NEIGHBOR EXPANDED SUM DISTINGUISHING INDEX ${ }^{1}$
}

\author{
Evelyne Flandrin $^{a}, \mathrm{HaO} \mathrm{Li}^{a}{ }^{a}$, Antoni MarczyK ${ }^{b, 2}$ \\ JeAn-FrançOIS SAClé $^{a}$ AND MARIUSz WoźniaK ${ }^{b}$ \\ ${ }^{a}$ LRI, UMR 8623, Université de Paris-Sud \\ Bt. 650 , rue Noetzlin, Gif-sur-Yvette, France \\ ${ }^{b}$ AGH University, Department of Discrete Mathematics \\ Al. Mickiewicza 30, 30-059 Kraków, Poland \\ e-mail: marczyk@agh.edu.pl
}

\begin{abstract}
A total $k$-coloring of a graph $G$ is a coloring of vertices and edges of $G$ using colors of the set $[k]=\{1, \ldots, k\}$. These colors can be used to distinguish the vertices of $G$. There are many possibilities of such a distinction. In this paper, we consider the sum of colors on incident edges and adjacent vertices.
\end{abstract}

Keywords: general edge coloring, total coloring, neighbor-distinguishing index, neighbor sum distinguishing coloring.

2010 Mathematics Subject Classification: 05C15.

\section{REFERENCES}

[1] J.A. Bondy and U.S.R. Murty, Graph Theory with Applications (Macmillan, London, 1976).

[2] M. Kalkowski, A Note on the 1,2-Conjecture (Ph. D. Thesis, Adam Mickiewicz University in Pozna'n, 2010).

[3] M. Kalkowski, M. Karoński and F. Pfender, Vertex-coloring edge-weightings: Towards the 1-2-3-Conjecture, J. Combin. Theory Ser. B 100 (2010) 347-349. doi:10.1016/j.jctb.2009.06.002

\footnotetext{
${ }^{1}$ The work of the third author was partially supported by the Polish Ministry of Science and Higher Education. The research of the fifth author was supported by the Polish National Science Center grant no. DEC-2013/09/B/ST1/01772.

${ }^{2}$ Corresponding author.
} 
[4] M. Karoński, T. Luczak and A. Thomason, Edge weights and vertex colours, J. Combin. Theory Ser. B 91 (2004) 151-157.

doi:10.1016/j.jctb.2003.12.001

[5] J. Przybyło and M. Woźniak, On a 1,2 Conjecture, Discrete Math. Theor. Comput. Sci. 12 (2010) 101-108.

Received 26 June 2015

Revised 1 February 2016

Accepted 1 February 2016 